\title{
Technical note: Automatic evaluation of infrared thermal images by computerized active shape modeling of bovine udders challenged with Escherichia coli
}

\author{
S. Watz, ${ }^{1 *}$ W. Petzl, ${ }^{1}$ H. Zerbe, ${ }^{1}$ A. Rieger,${ }^{1}$ A. Glas, ${ }^{1}$ W. Schröter, ${ }^{2}$ T. Landgraf, ${ }^{2}$ and M. Metzner ${ }^{1}$ \\ ${ }^{1}$ Clinic for Ruminants with Ambulatory and Herd Health Services, LMU Munich, Sonnenstrasse 16, 85764 Oberschleissheim, Germany \\ ${ }^{2}$ Fraunhofer Institute for Transportation and Infrastructure Systems IVI, Zeunerstrasse 38, 01069 Dresden, Germany
}

\begin{abstract}
Mastitis causes substantial economic losses and animal suffering in the dairy industry. The trend toward larger herd sizes complicates the monitoring of udder health in individual animals. Infrared thermography has successfully been used for early mastitis detection. However, manual thermogram analysis is time consuming and requires a skilled examiner, and automated image processing has not been tested. The aim of this study was to determine whether automatic evaluation of thermograms showed results comparable to those of manual evaluation of thermograms. Five healthy cows underwent an intramammary challenge with Escherichia coli to induce clinical mastitis. Multiple udder thermograms were taken every $2 \mathrm{~h}$ for $24 \mathrm{~h}$ before and after the challenge, resulting in 4,143 images in total. All images were evaluated using image recognition software (automatically) and a polygon tool (manually) to calculate the average and maximum surface temperatures. Because of the slightly different regions of interest, temperatures ascertained from the thermograms using the automatic method were consistently lower than those ascertained using the manual method. However, average udder surface temperatures evaluated using both methods were strongly correlated $(\mathrm{r}=0.98$ in the left hindquarter, and $\mathrm{r}=0.99$ in the right hindquarter) and showed maximum temperature peaks at the same time, 13 and $15 \mathrm{~h}$ after intramammary challenge. In the receiver operating characteristic analysis, both methods provided good results for sensitivity and specificity in detecting clinical E. coli-induced mastitis at different threshold values. For automatically evaluated maximum right hindquarter temperature, sensitivity was $93.75 \%$ and specificity was $94.96 \%$, and for manually evaluated maximum right hindquarter
\end{abstract}

Received September 28, 2018.

Accepted January 28, 2019.

*Corresponding author: sophie.watz@outlook.com temperature, sensitivity was $93.75 \%$ and specificity was $96.40 \%$. Thus, automatic thermogram evaluation is a promising tool for automated mastitis detection.

Key words: mastitis, thermography, udder, dairy cow

\section{Technical Note}

Mastitis is one of the most common diseases in dairy cows and it causes substantial economic losses (Rollin et al., 2015; van Soest et al., 2016) and suffering in affected animals. Infrared thermography has been used successfully for early mastitis detection (Metzner et al., 2015). The current gold-standard method for manually evaluating thermograms, however, is time consuming and requires a skilled examiner (Metzner et al., 2014). Because of growing herd sizes in the dairy industry, automated systems that enable animal health monitoring are required. Zaninelli et al. (2018) used software that located the pixel with the highest temperature inside an udder thermogram to distinguish between cows with normal and elevated SCC. A method for processing thermograms using automated image recognition software that recognizes the shape of the udder to detect mastitis has not been investigated to date. The objective of this study was to assess whether evaluation of bovine udder thermograms using automatic image recognition software provides results comparable to those of manual evaluation in detecting clinical Escherichia coli-induced mastitis. Using the automatic evaluation method, we also questioned whether the exclusion of typical "hot spots" (udder-thigh cleft and intermammary sulcus), which likely show temperatures that are closely related to inner body temperature (Metzner et al., 2014), leads to a depiction of the local inflammation processes in the udder. Thus, we used thermograms collected during an experimental infection study (approved by the ethics committee of the government of Upper Bavaria; reference: 55.2-1-54-2531-108-05), in which 5 healthy Holstein-Friesian dairy cows were injected with 500 cfu of $E$. coli (diluted in $2 \mathrm{~mL}$ of isotonic sterile saline solution) into the right hindquarter via the teat canal. 


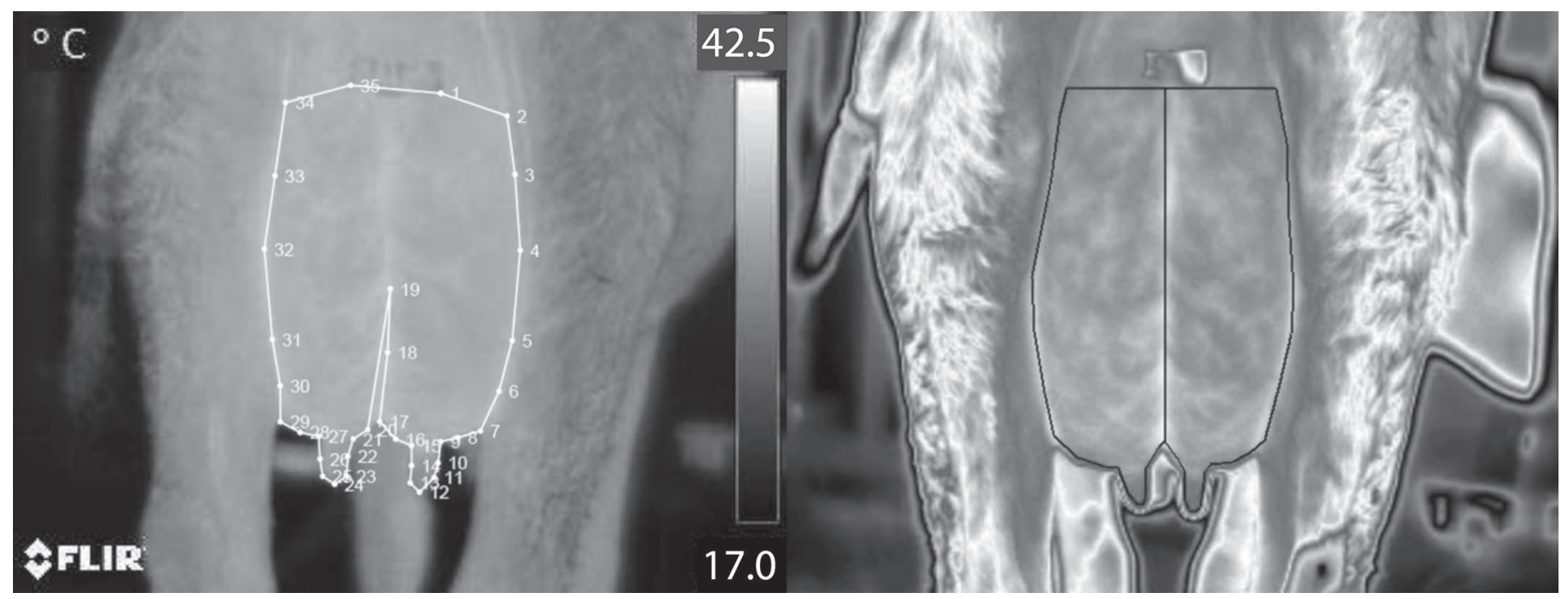

Figure 1. Depiction of automatic (left) and manual (right) thermogram evaluation. In automatic udder segmentation, based on the active shape approach, 35 landmarks define the udder silhouette. In the second step, the landmarks are connected in the regions of interest on the left and right hindquarter. The automatic detection of their position is based on a previously acquired point-distribution model. Manual segmentation of the silhouette of the left and right hindquarters was performed using a polygon tool (ThermaCAM Researcher Pro 2.8, FLIR Systems, Wilsonville, OR).

The left hindquarter was treated with $2 \mathrm{~mL}$ of isotonic sterile saline solution as a placebo control. All cows that were challenged with E. coli subsequently developed signs of clinical mastitis. During the $24 \mathrm{~h}$ before challenge and the $24 \mathrm{~h}$ after challenge, thermograms of the hind udder surface were taken at 2-h intervals using a ThermaCAM B20 HSV infrared camera (FLIR Systems, Wilsonville, OR). At each measurement, multiple thermograms were recorded, resulting in 4,143 images that were used to train the software. For evaluation, 3 consecutive thermograms were selected from each measurement series. From each triplicate of thermograms selected, the mean values were generated as described below.

Thermogram recording was performed in the barn where the animals were housed. Cows were fixed in the feeding fence and their tails were tied aside. At the rear side of the udder, a patch of adhesive tape was placed at the height of the knee joints, to serve as a marker (Figure 1). Thermograms were taken of both hindquarters. The examiner with the thermal camera was located behind the cow. An ultrasonic distance sensor (Stellar Products, Hilden, Germany) was used to ensure a constant distance of $1.8 \mathrm{~m}$ between the camera and the udder surface, and the camera's focus was adjusted automatically. Emissivity correction was implemented, setting the number of emissivity manually before measurements. For the udder surface, an emissivity of 0.96 was selected. Immediately after each thermal recording, we measured the animal's rectal temperature using a digital thermometer (Microlife AG, Widnau, Switzerland). Environmental temperature and humidity were recorded using a data logger (PCE Instruments, Meschede, Germany). A detailed description of the material and methods as well as the course of changes in udder surface temperature is given by Metzner et al. (2014).

The same thermograms were evaluated using 2 methods. Software for automatic evaluation of the thermograms based on the "active shape model" approach was developed and trained with the help of the 4,143 thermal udder images (Schröter, 2015). The software detected the silhouette of the udder (see Figure 1) and created 2 regions of interest (ROI) in each thermogram: the hind surface of the udder including the teats, which were divided into the left (HL) and right (HR) hindquarters. In a second step, $5 \%$ of the pixels inside each ROI, originating from the outer borders, were automatically excluded. To compare the manual evaluation with the automatic evaluation, thermograms were evaluated using software for manual evaluation, ThermaCAM Researcher Pro 2.8 (FLIR Systems). Values for environmental humidity, environmental temperature, and emissivity that were adjusted in the camera's settings during recording were taken into account by the software. The same ROI were selected but without exclusion of hot spots (Figure 1). For this purpose, the polygon tool was used. The outer borders for the ROIs were set manually and aligned with adhesive tape marking the proximal udder region, the intermammary 
Table 1. Pearson correlation coefficients (r) and differences between automatic and manual methods of evaluation of thermograms

\begin{tabular}{lcc}
\hline Variable $^{1}$ & $\mathrm{r}$ & Difference $^{2}\left({ }^{\circ} \mathrm{C}\right)$ \\
\hline $\mathrm{T}_{\max }$ of HL & $0.92^{*}$ & 0.77 \\
$\mathrm{~T}_{\max }$ of HR & $0.90^{*}$ & 1.09 \\
$\mathrm{~T}_{\text {avg }}$ of HL & $0.98^{*}$ & 0.72 \\
$\mathrm{~T}_{\text {avg }}$ of HR & $0.99^{*}$ & 0.71 \\
\hline
\end{tabular}

${ }^{1}$ Maximum $\left(\mathrm{T}_{\max }\right)$ and average $\left(\mathrm{T}_{\mathrm{avg}}\right)$ surface temperature of the left, placebo-treated hindquarter (HL) and the right, Escherichia coli-challenged hindquarter $(\mathrm{HR})$

${ }^{2}$ Median values.

$* P<0.05$.

sulcus in the median, and the udder-thigh clefts as lateral boundaries. The contrast between the environment and the distal udder indicated the teats. Manual ROI selection was repeated for every image. For each method and each thermogram, the maximum surface temperature $\left(\mathbf{T}_{\max }\right)$ and average surface temperature $\left(\mathbf{T}_{\text {avg }}\right)$ inside the ROI were acquired.

Automatic evaluation had a low rate of falsely detected outer udder borders (2-3\% of the thermograms). Manually determined temperatures were consistently higher than automatically analyzed values, with median differences ranging between 0.71 and $1.09^{\circ} \mathrm{C}$ depending on the evaluation parameter (Table 1). However, Pearson correlation analysis indicated that results of both methods were highly correlated $(\mathrm{r}=0.98$ and $\mathrm{r}$ $=0.99$ for $\mathrm{T}_{\text {avg }}$ of $\mathrm{HL}$ and $\mathrm{HR}$, respectively). All cows showed fever (rectal temperature $\geq 39.5^{\circ} \mathrm{C}$ ) after $E$. coli challenge, peaking 13 and $15 \mathrm{~h}$ after challenge (median $=41.2^{\circ} \mathrm{C}$ and $40.8^{\circ} \mathrm{C}$, respectively). For both methods, surface $\mathrm{T}_{\mathrm{avg}}$ and $\mathrm{T}_{\max }$ peaked in the challenged and placebo-treated quarter within a similar timespan (Table
2 ). The $T_{\max }$ peaks were equally high in both quarters and the $\mathrm{T}_{\text {avg }}$ peak was lower in the challenged quarter than in the placebo quarter. Results of the automatic evaluation showed a weaker correlation with rectal temperature compared with the manual evaluation, but the correlation coefficients were still moderately high (see Table 2). Temperature values 1 to $21 \mathrm{~h}$ after challenge were compared with those measured $24 \mathrm{~h}$ earlier and the differences were tested for significance using a oneway ANOVA and Dunnett's post hoc test. Both methods detected significant differences in maximum udder temperature 13 and $15 \mathrm{~h}$ after challenge $(P<0.05)$. Median $\mathrm{T}_{\max }$ in the $\mathrm{HR}$ was $36.31^{\circ} \mathrm{C}$ before challenge and $38.71^{\circ} \mathrm{C} 13 \mathrm{~h}$ after challenge using the automatic method. Using the manual method, median $\mathrm{T}_{\max }$ in the $\mathrm{HR}$ was $37.31^{\circ} \mathrm{C}$ before challenge and $39.64^{\circ} \mathrm{C} 13 \mathrm{~h}$ after challenge. Differences in average udder temperature were not significant using either method. The ROC analysis indicated that values measured at times when cows showed signs of clinical mastitis and fever (rectal temperature $\geq 39.5^{\circ} \mathrm{C}$ ) were the opposite of values measured when cows were healthy. The ROC analysis was performed separately for each method, each hindquarter, and for $\mathrm{T}_{\max }$ and $\mathrm{T}_{\mathrm{avg}}$ (Table 2). The maximum sum of the sensitivity and specificity was considered the optimum, and the associated temperature value was chosen as the threshold. Both methods provided good results for sensitivity and specificity in detecting clinical E. coli-induced mastitis that was accompanied by fever (Table 2).

Automatic evaluation of thermograms of bovine udders that received an intramammary challenge with $E$. coli showed good results for detecting clinical mastitis, and these results were valid compared with the cur-

Table 2. Maximum $\left(\mathrm{T}_{\max }\right)$ and average $\left(\mathrm{T}_{\text {avg }}\right)$ surface temperature of the left, placebo-treated hindquarter (HL) and the right, Escherichia colichallenged hindquarter (HR) evaluated from thermograms using an automatic or manual method of evaluation

\begin{tabular}{|c|c|c|c|c|c|c|}
\hline $\begin{array}{l}\text { Evaluation } \\
\text { method }\end{array}$ & Variable & 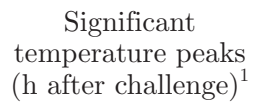 & $\begin{array}{c}\text { Sensitivity }^{2} \\
(\%)\end{array}$ & $\begin{array}{c}\text { Specificity }^{2} \\
(\%)\end{array}$ & $\begin{array}{l}\text { Threshold }{ }^{2} \\
\left({ }^{\circ} \mathrm{C}\right)\end{array}$ & $\begin{array}{c}\text { Correlation between } \\
\text { variable and rectal } \\
\text { temperature }^{3}\end{array}$ \\
\hline \multirow[t]{3}{*}{ Automatic } & $\mathrm{T}_{\max }$ of $\mathrm{HL}$ & $13^{*}, 15^{*}$ & 81.25 & 92.09 & $>37.50$ & $0.74^{*}$ \\
\hline & $\mathrm{T}_{\text {avg }}$ of $\mathrm{HL}$ & - & 75.00 & 92.09 & $>35.83$ & $0.57^{*}$ \\
\hline & $\mathrm{T}_{\text {avg }}$ of $\mathrm{HR}$ & - & 62.50 & 92.81 & $>35.80$ & $0.49^{*}$ \\
\hline Manual & $\mathrm{T}_{\max }$ of $\mathrm{HL}$ & $13^{*}, 15^{*}$ & 93.75 & 92.09 & $>38.07$ & $0.80^{*}$ \\
\hline
\end{tabular}

${ }^{1}$ Differences in temperature values after challenge and temperature values measured $24 \mathrm{~h}$ before testing for significance using a one-way ANOVA and Dunnett's post hoc test.

${ }^{2}$ Results of the receiver operating characteristic analysis, which tested each variable's ability to detect periods of fever (rectal temperature $\left.\geq 39.5^{\circ} \mathrm{C}\right)$.

${ }^{3}$ Results of Pearson correlation analysis.

$* P<0.05$. 
rent gold standard of manual evaluation. Additionally, automatic evaluation had a good detection rate.

We presumed that the higher temperatures observed using manual analysis occurred because warmer regions were included, such as the udder-thigh cleft, whereas automatic segmentation omits these regions. Exclusion of hot spots reduced the effect of rectal temperature on the evaluation results; however, automatic evaluation did not result in better detection of acute $E$. coli mastitis.

We found that the evaluation parameters $T_{\max }$ and $\mathrm{T}_{\text {avg }}$ were useful in evaluating udder thermograms. However, $\mathrm{T}_{\max }$ proved more suitable for detection of significant temperature differences and had better sensitivity and specificity results than $\mathrm{T}_{\text {avg. }}$.

In this study, we detected a significant temperature elevation starting $13 \mathrm{~h}$ after the challenge. This is a promising (short) amount of time in terms of aiming for successful treatment of clinical E. coli mastitis. When applying this method in the field, the time of the challenge with a pathogen would be unknown and different reasons for the temperature elevation would have to be considered. This method may also depict changes in the inner core temperature, such as fever. However, infrared thermography is intended for use as an automatic health surveillance tool and should not replace examination of individual animals. The fact that it also identifies fever should not be regarded as a disadvantage; animals that have abnormal udder skin surface temperatures will be identified quickly and can be assessed in detail. This is a promising approach because thermography has been used successfully to monitor other inflammatory and infectious processes in cattle, such as omphalitis in newborn calves (Shecaira et al., 2018) and digital dermatitis in dairy cows (Harris-Bridge et al., 2018).

However, this method's ability to detect subclinical mastitis or clinical mastitis caused by other pathogens should be assessed in further research because recent findings emphasize the distinctly different host responses toward mastitis-causing pathogens (Lind et al., 2015; Petzl et al., 2016). The host responses were distinct during E. coli- and Staphylococcus aureus-induced mastitis (Petzl et al., 2016) but the pathogen-specific extent of the inflammatory response was always detectable. Additionally, Lind et al. (2015) showed that the tissue response on Fürstenberg's rosette and the teat cistern toward either E. coli LPS or Staph. aureus lipoteichoic acid (LTA) was significantly higher for LPS than for LTA.

A simple comparison of temperatures in the HL and HR was not sufficient to detect acute $E$. coli mastitis. The average temperature increase was lower in the challenged quarter, which was likely because of edema.
This assumption is based on the observation that the regions of lower surface temperatures in the thermograms were associated with the regions where edema occurred. We observed distinct temperature increases in both the challenged quarter and neighboring quarter, so we assume that $E$. coli mastitis in the forequarters could be detected by screening the maximum temperature of the hindquarters. Temperature increases began $11 \mathrm{~h}$ after challenge and were significant 13 and $15 \mathrm{~h}$ after challenge, but temperatures declined by $17 \mathrm{~h}$ after challenge: $T_{\max }$ was no longer significantly different from $\mathrm{T}_{\max }$ before challenge. Therefore, for reliable udder health monitoring, recording of udder thermograms should be implemented in intervals not exceeding $2 \mathrm{~h}$, at least for the detection of clinical E. coli mastitis. If $\mathrm{T}_{\max }$ or $\mathrm{T}_{\text {avg }}$ exceeds a specific threshold (Table 2), cows should be assessed in detail.

This raises the question of where the infrared thermography camera for automatic health supervision should be positioned. A position where the animals can be recorded multiple times throughout the day is recommended; for instance, places that are highly frequented in a free-range barn, such as feeding stations or cow brush arrangements. However, lower-ranking cows may have less access to these areas. Diseased cows are expected to move less and could evade automated monitoring. Nevertheless, automated health supervision should be a tool to detect pathological alterations before clinical symptoms appear. Enhancing monitoring with accelerometers could be a strategy to minimize these limitations. Installing the camera in the milking parlor may be questionable because intervals between measurements would extend up to $12 \mathrm{~h}$ and temperature peaks lasting 2 or $3 \mathrm{~h}$ may be missed. Consequently, field studies testing different positioning of thermography cameras and involving a larger number of cows are needed.

\section{REFERENCES}

Harris-Bridge, G., L. Young, I. Handel, M. Farish, C. Mason, M. A. Mitchell, and M. J. Haskell. 2018. The use of infrared thermography for detecting digital dermatitis in dairy cattle: What is the best measure of temperature and foot location to use? Vet. J. 237:26-33. https://doi.org/10.1016/j.tvjl.2018.05.008.

Lind, M., A. S. Sipka, H. J. Schuberth, A. Blutke, R. Wanke, C. Sauter-Louis, K. A. Duda, O. Holst, P. Rainard, P. Germon, H. Zerbe, and W. Petzl. 2015. Location-specific expression of chemokines, TNF- $\alpha$ and S100 proteins in a teat explant model. Innate Immun. 21:322-331. https://doi.org/10.1177/1753425914539820.

Metzner, M., C. Sauter-Louis, A. Seemueller, W. Petzl, and W. Klee. 2014. Infrared thermography of the udder surface of dairy cattle: characteristics, methods, and correlation with rectal temperature. Vet. J. 199:57-62. https://doi.org/10.1016/j.tvj1.2013.10.030.

Metzner, M., C. Sauter-Louis, A. Seemueller, W. Petzl, and H. Zerbe. 2015. Infrared thermography of the udder after experimentally in- 
duced Escherichia coli mastitis in cows. Vet. J. 204:360-362. https: //doi.org/10.1016/j.tvjl.2015.04.013.

Petzl, W., J. Gunther, K. Muhlbauer, H. M. Seyfert, H. J. Schuberth, J. Hussen, C. Sauter-Louis, A. Hafner-Marx, and H. Zerbe. 2016 Early transcriptional events in the udder and teat after intra-mammary Escherichia coli and Staphylococcus aureus challenge. Innate Immun. 22:294-304. https://doi.org/10.1177/1753425916640057.

Rollin, E., K. C. Dhuyvetter, and M. W. Overton. 2015. The cost of clinical mastitis in the first 30 days of lactation: An economic modeling tool. Prev. Vet. Med. 122:257-264. https://doi.org/10.1016/j .prevetmed.2015.11.006.

Schröter, W. 2015. Automatisierte Analyse von veterinären Wärmebildern. MS Thesis. Faculty of Electrical Engineering and Computer Sciences, University Zittau, Görlitz, Germany.
Shecaira, C. L., C. H. Seino, J. A. Bombardelli, G. A. Reis, E. J. Fusada, M. R. Azedo, and F. J. Benesi. 2018. Using thermography as a diagnostic tool for omphalitis on newborn calves. J. Therm. Biol. 71:209-211. https://doi.org/10.1016/j.jtherbio.2017.11.014.

van Soest, F. J. S., I. Santman-Berends, T. Lam, and H. Hogeveen. 2016. Failure and preventive costs of mastitis on Dutch dairy farms. J. Dairy Sci. 99:8365-8374. https://doi.org/10.3168/jds .2015-10561.

Zaninelli, M., V. Redaelli, F. Luzi, V. Bronzo, M. Mitchell, V. Dell'Orto, V. Bontempo, D. Cattaneo, and G. Savoini. 2018. First evaluation of infrared thermography as a tool for the monitoring of udder health status in farms of dairy cows. Sensors (Basel) 18:E862. https://doi.org/10.3390/s18030862. 